\title{
Tecendo Fios Entre o Feminismo Latino-Americano Descolonial e os Estudos Pós-Coloniais Latino- Americanos
}

\section{Resumo}

\author{
Sartore, Anna Rita ${ }^{1}$
}

Santos, Aline Renata dos ${ }^{2}$

Silva, Camila Ferreira da ${ }^{3}$

O presente trabalho tem por objetivo realizar aproximações epistemológicas entre o Feminismo Latino-americano Descolonial, Curiel, (2009); Mohanty, (2008); Paredes, (2010); Espinosa-Miñoso, (2014, 2013), e os Estudos Pós-coloniais Latino-americanos Dussel, (1994); Quijano, (2000, 2005); Mignolo (2011); Porto-Gonçalves, (2009). Utilizamo-nos da pesquisa bibliográfica e da Análise de Conteúdo via Análise Temática Bardin, (2011), Vala (1986). As aproximações epistemológicas do Feminismo Latinoamericano Descolonial com os Estudos Pós-Coloniais Latino-americanos ocorrem na medida em que questionam o lócus de enunciação de conhecimento eurocêntrico e suas formas de produção prescritas como válidas e universais e apontam para a valorização e a legitimação de outros loci de enunciação que produzam conhecimentos outros. $O$ entrelaçamento destas abordagens permite-nos compreender as mulheres latinas americanas como protagonistas de lutas políticas e epistêmicas na construção e na constituição de uma sociedade despatriarcalizada.

Feminismo Latino-americano Descolonial. Estudos Pós-coloniais Latino-americanos. Analise Temática

\begin{abstract}
o
El presente trabajo tiene el objeto de realizar aproximaciones epistemológicas entre el Feminismo Latinoamericano Decolonial Curiel, (2009); Mohanty, (2008); Paredes, (2010); Espinosa-Miñoso, (2014, 2013), y los Estudios Postcoloniales Latinoamericanos Dussel, (1994); Quijano, (2000, 2005); Mignolo (2011); Porto-Gonçalves, (2009). Hemos utilizado la investigación bibliográfica y el Análisis de Contenido vía Análisis Temático (BARDIN, 2011; VALA, 1986). Las aproximaciones epistemológicas del Feminismo Latinoamericano Decolonial con los Estudios Postcoloniales Latinoamericanos ocurren en la medida en que cuestionan el locus de enunciación de conocimiento eurocéntrico y sus formas de producción prescritas como válidas y universales y apuntan para la

\footnotetext{
1 Doutora e mestra em Educação pela Universidade de São Paulo (USP). Psicanalista. Licenciada em Pedagogia e Ciências Físicas e Biológicas. Professora Adjunta da Universidade Federal de Pernambuco.

2 Mestranda da Pós-Graduação em Educação pela Universidade Federal de Pernambuco. Licenciada em Pedagogia pela Universidade Federal de Pernambuco. Pertence ao Grupo de Estudos Pós-Coloniais Latino-Americanos, Teoria da Complexidade e Educação coordenado pelo Prof. Dr. Janssen Felipe da Silva PPGEdu/PPDEDUC-UFPE/CAA.

${ }^{3}$ Graduanda em Pedagogia na Universidade Federal de Pernambuco. Pertence ao Grupo de Estudos PósColoniais Latino-Americanos, Teoria da Complexidade e Educação coordenado pelo Prof. Dr. Janssen Felipe da Silva PPGEdu/PPDEDUC-UFPE/CAA.
} 
valoración y legitimación de otros loci de enunciación que produzcan otros conocimientos. El entrelazamiento de estos abordajes nos permite comprender a las mujeres latinoamericanas como protagonistas de luchas políticas y epistémicas en la construcción y en la constitución de una sociedad despatriarcalizada.

Feminismo Latinoamericano Descolonial. Estudios Postcoloniales Latinoamericanos. Análise Temática.

\section{Introdução}

O presente trabalho tem por objetivo analisar aproximações epistemológicas entre o Feminismo Latino-americano Descolonial e os Estudos Pós-coloniais Latino-americanos. Tais aproximações constituem a discussão teórica das seguintes pesquisas: a) de mestrado do Programa de Pós-Graduação em Educação da UFPE, que trata da presença do patriarcado nas imagens dos livros didáticos específicos para as escolas localizadas no território campesino e; b) do Programa de Iniciação Científica, que aborda a presença da Negra nos livros didáticos específicos para as escolas localizadas no território campesino. Ambas as pesquisa fazem parte do Grupo de Pesquisa Estudos Pós-Coloniais Latinoamericanos, Teoria da Complexidade e Educação. Para isto, destacamos os seguintes conceitos do Feminismo Latino-americano Descolonial: a) patriarcado colonial-moderno; b) feminismos; c) gênero; d) autonomia; e) despatriarcalização, tomando como autoras de referência: Curiel (2009); Mohanty (2008); Paredes (2010) e Espinosa-Miñoso (2014; 2013). Também frisamos determinados conceitos dos Estudos Pós-coloniais Latino-americanos, a saber: a) colonialismo-colonização; b) racionalização; c) racialização; d) colonialidade nos eixos do poder; do ser; e do saber; e) diferença colonial; f) geopolítica; g) corpo-política; h) descolonização, tendo como autores de referência: Dussel (1994); Quijano (2000; 2005); Mignolo (2011); PortoGonçalves (2009) e Silva (2014; 2015). Utilizamo-nos da pesquisa bibliográfica e da Análise de Conteúdo, via Análise Temática por meio de Bardin (2011) e Vala (1986).

Partimos da compreensão de que as mulheres latino-americanas racializadas têm constituído e construído feminismos ${ }^{i}$ que intencionam romper com o patriarcado colonial-moderno que foi fundado através dos processos de 
colonialismo e colonização da Abya Yalaii na formação do sistema mundo moderno/colonial.

O Feminismo Latino-americano Descolonial retira a cortina de fumaça que oculta e desvirtua os conhecimentos; as formas de viver; as culturas e as histórias das mulheres latino-americanas. Para isto, parte de dois movimentos simultâneos: a) o primeiro se dá com o questionamento do Feminismo Hegemônico que têm reproduzido relações coloniais; b) o segundo movimento acontece através da construção de uma teoria política e epistemológica propositiva tecida na América Latina (Paredes, 2010).

Enquanto o primeiro movimento denuncia a relação saber-poder imposta pelo Feminismo Hegemônico que mira as mulheres latino-americanas como vítimas e que não possuem conhecimento, o segundo articula-se ao primeiro na medida em que o Feminismo Latino-americano Descolonial tem realizado uma virada epistêmica, enraizada no território da Abya Yala. De acordo com EspinosaMiñoso (2014), isto acontece por meio da recuperação das tradições e dos saberes das mulheres racializadas da Abya Yala.

As aproximações epistemológicas com os Estudos Pós-coloniais Latinoamericanos subsidiam a compreensão de como se deu a instauração e imposição do modelo de sociedade patriarcal moderno/colonial através do processo de colonialismo, no nascimento do sistema mundo moderno/colonial. A título de organização, o artigo está dividido nas seguintes seções: a) Origem do Feminismo Latino-americano Descolonial; b) Aproximações epistemológicas entre Feminismo Latino-americano Descolonial e os Estudos Pós-coloniais Latino-americanos e; c) Primeiras considerações.

\section{Feminismo Latino-americano Descolonial}

O Feminismo Latino-americano Descolonial surge dos reclamos das mulheres da Abya Yala que historicamente foram vistas como incapazes de construir epistemologias enraizadas em seus territórios. O referido Feminismo encontrase em construção de uma genealogia do pensamento produzido desde as mulheres latino-americanas racializadas e subalternizadas. Dialoga com epistemologias geradas por intelectuais e ativistas, ao realizar uma virada 
epistêmica no intuito de desconstruir a matriz de poder fundada com o nascimento do Sistema mundo colonial/moderno.

O Feminismo Latino-americano Descolonial aproxima-se dos Estudos Póscoloniais Latino-americanos na medida em que este realiza rachaduras epistêmicas ao denunciar as formas de exploração e de opressão sofridas pelos povos da Abya Yala durante o processo de Colonialismo que se reeditam através das heranças coloniais. Destacamos que as mulheres, durante o processo de colonização colonialismo, foram exploradas duplamente, a saber: por ser mulher e pela pertença a raças classificadas e hierarquizadas como inferiores, neste caso, índias e negras.

O Feminismo Latino-americano Descolonial tem suas bases epistêmicas fundadas em distintas experiências, sendo elas:

los movimientos indígenas, afros, de mujeres, feminismo de color en los Estados Unidos (EE UU), feminismo antirracista, feminismo autónomo, movimiento de carácter mixto, generacionales, como Hijos e Hijas por la Memoria y contra la Impunidad, Incite! Women of Color Unite, movimientos radicales de la disidencia sexual, entre otros (ESPINOSA MIÑOSO; GOMEZ; LUGONES; OCHOA, 2013, p. 403, 404).

Estas experiências estão ancoradas em contextos específicos da Abya Yala, fundadas em corpos e territórios distintos que constituem contextos históricos nos quais as feministas descoloniais realizam os seus quefazeres (Freire, 1996). Segundo Espinosa Miñoso (et al. 2013), o Feminismo Latino-americano Descolonial diz respeito a uma transformação radical das relações sociais de poder que oprimem e subordinam as mulheres indígenas, afro e mestiças pobres na Abya Yala. Tal transformação busca a afirmação da vida das mulheres racializadas. Nessa direção, o Feminismo Latino-americano Descolonial empreende rupturas epistêmicas com o Feminismo Hegemônico; surge com a ilustração através de uma ideia de história linear e eurocêntrica, negando e ocultado outros lugares-tempos em que mulheres se colocam contra 0 patriarcado.

Segundo Paredes (2011), o patriarcado moderno/colonial é um sistema de morte, construído historicamente, atuando sobre o corpo das mulheres. Engloba costumes, tradições, normas, hábitos, ideias, símbolos, leis, entre outros, 
determinando, naturalizando e universalizando papéis e lugares das populações, de mulheres e de homens, em diferentes tempos e lugares.

O patriarcado moderno/colonial atinge a todas as mulheres, mas de formas e intensidade distintas de acordo com o contexto histórico, cultural, social, político e econômico de cada realidade. De acordo com Paredes,

el Patriarcado, se recicla y se nutre de los cambios sociales y revolucionarios de esta misma humanidad. Afina sus tentáculos, corrige sus formas brutales de operar y relanza las opresiones con instrumentos cada vez mas sutiles y difíciles de detectar y responder (2011, p.6).

Na década de 1990, o patriarcado se reestrutura através da institucionalização dos movimentos sociais, dentre estes, o Feminismo Latino-americano, visando com isso despolitizar os movimentos feministas na luta por libertação das opressões sofridas, via patriarcado. A institucionalização dos movimentos feministas refere-se a processos de cooptação de mulheres feministas para assumirem cargos dentro das organizações não governamentais (ONG). Segundo Paredes (2011), isto aconteceu sob o lema do empoderamento das mulheres latino-americanas racializadas, que se daria através do acesso ao mercado de trabalho. Tal empoderamento se deu por meio da escolarização técnica das mulheres, visto como forma de revolução. Contudo, a incorporação das mulheres ao mercado de trabalho é desigual, haja vista que as hierarquias entre homens e mulheres permanecem, fato evidenciado pelo fato de as mulheres latino-americanas racializadas ocuparem os mesmos cargos que homens recebendo remunerações inferiores.

A institucionalização dos movimentos sociais feministas trouxe, como central de sua análise, a categoria Gênero, categoria esta que, ao ser entendida dentro de um olhar eurocêntrico-moderno, limita as relações de opressões pautadas apenas pelo olhar das desigualdades entre homens e mulheres, silenciando as desigualdades de classe, de raça e de sexualidade. Segundo Valdivieso (2014), "el "género" no es suficiente para entender la situación de las mujeres negras, indígenas o mestizas, como tampoco para comprender las relaciones de subordinación que se dan entre mujeres por razones de clase" (p. 28). Nesta linha de raciocínio, a categoria gênero perde o seu potencial político ao 
homogeneizar as relações de poder, dado que desconsidera os contextos em que as relações de gênero ocorrem.

A partir desta institucionalização dos movimentos sociais surge, em contraposição, o movimento feminista autônomo que levanta a bandeira pela autonomia das mulheres, esta entendida "en primera instancia desde la autonomía de nuestros cuerpos de mujeres y hombres y de nuestras decisiones, remarcamos aquí la autonomía del cuerpo y las decisiones de las mujeres" (PAREDES, 2011, p. 14).

Assim, a luta pela autonomia das mulheres caminha para Despatriarcalização (PAREDES, 2011) entendida como um processo que visa romper com o sistema de dominação sobre o corpo das mulheres, o patriarcado.

\section{Aproximações epistemológicas entre Feminismo Latino- americano Descolonial e os Estudos Pós-coloniais Latino- americanos}

A expansão marítima mercantilista iniciada por volta de 1492 empreendida, principalmente, pelos portugueses e espanhóis foi espaço/tempo para a constituição e a difusão da racionalidade moderna/eurocêntrica, ou seja, a modernidade (DUSSEL, 1994). A invasão das terras "descobertas" instalou e determinou uma organização social, cultural, política e econômica de exploração e de dominação sobre os povos que ali estavam e dos que mais tarde foram sequestrados da África.

A invasão da Abya Yala resultou na instauração arbitrária de uma nova ordem de poder, direta e formal, de um povo "soberano", o europeu, sobre os povos que foram inferiorizados índios e negros. Além disto, este contexto de colonialismo espalhou-se por meio da colonização dos povos e das culturas dominadas em toda América e, posteriormente, no mundo. A colonização é uma etapa do colonialismo na qual se dá a imposição de um modelo único e universal de conhecer, de trabalho e de cultura legitimadas como avançadas e superiores sustentadas por um ideal de sujeito branco, europeu, heterossexual, cristão (QUIJANO, 2005) e masculino (SILVA, 2014). 
O modelo eurocêntrico de dominação e de exploração, empreendido com a invasão da Abya Yala, sustenta-se em dois pilares fundamentais: a Racionalização e a Racialização. O primeiro diz respeito à hegemonia dos conhecimentos produzidos pelos europeus e das formas de produção, sendo considerados os únicos detentores e legitimadores de epistemologias válidas. $O$ segundo dá-se com a construção mental da ideia de raça, que classifica e hierarquiza os povos em raças superiores e inferiores e mais especificamente em: brancos, índios, negros, mestiços e posteriormente em amarelos. Esta hierarquização e classificação distribuem lugares e papeis sociais de cada sujeito, grupo social e povo no sistema de dominação/exploração mundial (QUIJANO, 2005).

Destacamos que o Feminismo Hegemônico do Norte e do Suliii têm reproduzido a lógica de dominação instaurada com o colonialismo, tendo em vista que enxergam as mulheres latino-americanas através dos olhos do colonizador branco, europeu, heterossexual e cristão. Isto ocorre quando as mulheres da América Latina são tratadas como objeto de estudos e não como sujeitas produtoras de suas experiências históricas, políticas e epistemológicas. Segundo Mohanty

esta mujer promedio del tercer mundo lleva una vida esencialmente truncada debido a su género femenino (léase sexualmente constreñida) y su pertenencia al tercer mundo (léase ignorante, pobre, sin educación, limitada por lãs tradiciones, doméstica, restringida a la familia, víctima, etc.). Esto, sugiero, contrasta con la autorepresentación (implícita) de la mujer occidental como educada, moderna, en control de su cuerpo y su sexualidad y con la libertad de tomar sus propias decisiones (2008, p. 5).

Nesta linha de raciocínio, o Feminismo Hegemônico do Norte e do Sul reproduz a lógica da racionalização e da racialização, visto que estabelecem uma hierarquização entre mulheres civilizadas (europeias) e mulheres não civilizadas (latino-americanas). Esta hierarquização autoriza as mulheres europeias/eurocentradas a intervir com a sua missão civilizadora colonial/moderna, culminando na subalternização política e epistêmica das mulheres latino-americanas racializadas. 
Mesmo com a "descolonização" da América, ao deixar de ser colônia, o padrão mundial de poder moderno/colonial/patriarcal/capitalista/eurocêntrico não findou, ao contrário, permanece até a atualidade. Este encontrou novas formas de se travestir, para conservar a sua dominação através da colonialidade que

se funda en la imposición de una clasificación racial/étnica/ sexual/gênero de la población del mundo como piedra angular de dicho patrón de poder y opera en cada uno de los planos, ámbitos y dimensiones, materiales y subjetivas, de la existência social cotidiana y a escala societal. (QUIJANO, 2000, p. 342, grifo nosso).

A colonialidade é um processo arbitrário de dominação/exploração no qual o ideário colonial penetra as estruturas sociais tanto na dimensão material quanto na dimensão imaterial dos povos subjugados. Para Quijano (2005), há três eixos da colonialidade: do poder; do saber e do ser.

A colonialidade do poder refere-se à hierarquização racial dos povos entre inferiores e superiores, o que determina a distribuição e o controle do trabalho dos povos subalternizados mundialmente. A colonialidade do poder produz e reproduz dicotomias entre povos superiores e povos inferiores, no caso das mulheres do primeiro mundo (superiores) e das mulheres do terceiro mundo (inferiores).

A colonialidade do saber implica na negação e na invalidação dos conhecimentos dos não-europeus. Esse eixo da colonialidade legítima uma razão que produz conhecimento hegemônico/eurocêntrico e universal, por isso, válida. Como os povos subalternizados são tidos enquanto: primitivos, irracionais, iletrados e sem cultura, não são capazes de terem epistemologias válidas que produzam conhecimentos verdadeiros.

Essas manifestações da colonialidade se consolida na colonialidade do ser que denota a internalização da subalternidade do não-europeu, que passa a aceitar a imagem do colonizador como sua, ocultando a dominação colonial, o que Freire (2005) denomina da condição do oprimido enquanto hospedeiro do opressor. É o que tem ocorrido com o Feminismo Hegemônico do Sul ao utilizarse unicamente das teorias do Feminismo Hegemônico do Norte, subalternizando as teorias produzidas desde o território da Abya Yala. "Assim, forja-se uma relação de, no máximo, imitação dos sujeitos inferiores em relação aos modos 
de ser dos sujeitos classificados como superiores" (Silva; Silva, 2014). Desse modo, o Feminismo Hegemônico do Norte e do Sul reforçam a colonialidade, visto que negam e/ou silenciam "el racismo, la pobreza, la destitución, la deshumanización de la mujeres indígenas, afro y no blancas en general" (ESPINOSA-MIÑOSO, et al. 2013, p. 413). Desvelar o racismo, o etnocentrismo e o privilegio epistêmico do Feminismo Hegemônico do Norte e do Sul é tarefa fundante do Feminismo Latino-americano Descolonial, haja vista que as realidades, os anseios e as necessidades das mulheres Latino-americanas não são as mesmas das mulheres europeias e estadunidenses.

Desta feita, as mulheres subjugadas pela colonialidade resistem à dominação colonial afirmando-se como sujeitas de direito e epistêmicas, que evidenciam o seu lugar enquanto lócus de enunciação epistemológica, política e cultural, contrapondo-se aos laços de dominação impostos pelo invasor.

As resistências à dominação colonial decorrem na constituição da diferença colonial, que busca fraturar a estrutura de dominação colonial e ao fraturá-la ganhar espaço para a valorização e a legitimação dos seus conhecimentos. Segundo Mignolo,

la diferencia colonial crea condiciones para el desarrollo de situaciones dialógicas en las que una enunciación fracturada es representada desde la perspectiva subalterna como una respuesta al discurso y a la perspectiva hegemónica $(2011$, p. 9).

As feministas descoloniais têm realizado o revide epistêmico através de rupturas políticas e epistemológicas, na medida em que articulam raça, etnia, classe e sexualidade como categorias constitutivas da colonialidade. No caso do Feminismo Latino-americano Descolonial,

la descolonización para nosotras se trata de una posición política que atraviesa el pensamiento y la acción individual y colectiva, nuestros imaginarios, nuestros cuerpos, nuestras sexualidades, nuestras formas de actuar y de ser en el mundo y que crea una especie de "cimarronaje" intelectual, de prácticas sociales y de la construcción de pensamiento propio de acuerdo a experiencias concretas (CURIEL, 2009, p. 3).

Assim, descolonizar-se é liberar-se das amarras imperiais que situam as mulheres latino-americanas racializadas como vítimas passivas a opressões e explorações, impostas pelo patriarcado colonial-moderno. Os reclamos do 
Feminismo Latino-americano Descolonial tem o intuito de resgatar as histórias de mulheres que historicamente foram excluídas, marginalizadas e silenciadas, pelo ideário eurocêntrico de sujeito universal, branco, heterossexual e cristão (PAREDES, 2010) e masculino (SILVA, 2014).

Para tanto, o Feminismo Latino-americano Descolonial questiona a geo-política e a corpo-política do conhecimento (GROSFOGUEL, 2008). A geo-política do conhecimento refere-se às epistemologias hegemônicas da modernidade que são condizentes com os interesses geográficos e políticos do Norte Silva, (2014; 2015). O lugar geográfico não diz respeito, necessariamente, ao lugar de produção epistêmica, haja vista que é possível adotar epistemologias produzidas no Norte e pertencer ao Sul subalternizado. Silva (2014, 2015). A corpo-política do conhecimento diz respeito à epistemes hegemônicas do Norte constituídas por meio da superioridade de gênero, de raça, de classe e de sexualidade, visto que estabelece como sujeito produtor de epistemologias válidas o homem, branco, burguês, heterossexual e cristão.

Neste ínterim, o Feminismo Latino-americano Descolonial denuncia por meio do revide epistêmico, que a geopolítica do pensamento feminista latino-americano esteve historicamente sobre os domínios do Feminismo Hegemônico do Norte. Em relação a "ego-política do conhecimento", esta permaneceu sobre os domínios de mulheres brancas, burguesas e heterossexuais. O revide epistêmico do Feminismo Latino-americano Descolonial ocorre com a ruptura do lugar de produção de conhecimento e de quem dita o que é conhecimento válido.

\section{Considerações iniciais}

Percebemos, através das primeiras aproximações entre o Feminismo Latinoamericano Descolonial e os Estudos Pós-coloniais Latino-americanos, que ambas as teorias têm empreendido rupturas políticas e epistêmicas com o eurocentrismo. Deste modo, estas teorias assinalam para a necessidade de recuperar e valorizar os saberes ancestrais, isto é, descolonizar-se dos moldes eurocêntricos universais de sujeito, de saber, de cultura, entre outros.

Nessa direção, o referido Feminismo busca pela descolonização dos corpos das mulheres. Para isto, concebe o patriarcado enquanto um sistema de dominação 
instaurado com o processo de colonialismo e colonização da Abya Yala, que sobrevive atualmente através de heranças patriarcais presentes em todas as instâncias da vida sejam elas relacionadas a relações sociais interpessoais, econômicas, políticas, educativas, dentre outras.

Assim, entendemos que o Feminismo Latino-americano Descolonial é constituído por meio de processos de: a) confrontação, na medida em que questiona as categorias mulher universal e gênero, desvelando a colonialidade presente no Feminismo Hegemônico do Norte e do Sul; b) desconstrução, visto que as mulheres latino-americanas passam a desmontar as teias que as oprimem e as colocam em uma posição de consumidoras da epistemologia do Feminismo Hegemônico do Norte e do Sul e; c) construção, uma vez que as mulheres latino-americanas racializadas passam a recuperar as experiências políticas e epistemológicas de suas ancestrais na construção de um Feminismo Descolonial desde a Abya Yala, (PAREDES, 2010).

Em suma, ressaltamos, ainda, que ambas as teorias nos mostram correlações entre seus conceitos que nos ajudam a olhar para as mulheres latino-americanas racializadas não como vítimas, mas como protagonista de lutas por libertação do sistema de morte que é o patriarcado. Além disso, tais aproximações caminham para a compreensão de processos de descolonização que no caso do Feminismo Latino-americano acontece por meio da Despatriarcalização.

\section{Referências}

BARDIN, Laurance. Análise de conteúdo. Lisboa: Edições 70, 2011.

CURIEL, Ochy. Descolonizando el Feminismo: una perspectiva desde America Latina y el Caribe. Primer Coloquio Latinoamericano sobre Praxis y Pensamiento Feminista, realizado en Buenos Aires en junio de 2009.

DUSSEL, Enrique. 1492: El Encubrimiento del Otro: hacia el origen del "mito dela modernidad. Plural Editores. La Paz, 1994.

ESPINOSA-MIÑOSO, Yuderkys. Etnocentrismo y Colonialidad en los Feminismos Latinoamericanos: complicidades y consolidación de las hegemonías feministas en el espacio transnacional. Revista Venezolana de Estudios de la Mujer, Julio/Diciembre. Vol. 14. № 33 - Pp. 37-54, 2009.

ESPINOSA-MIÑOSO, Yuderkys. Una crítica descolonial a la epistemología feminista crítica. El Cotidiano, marzo-abril, 2014. 
ESPINOSA-MIÑOSO, Yuderkys; Gomez, Diana; Lugones, María; Ochoa, Karina.

Reflexiones Pedagógicas en torno al Feminismo Descolonial: una conversa en cuatros voces. En WALSH, Catherine. (Org.). Pedagogías Decoloniales: prácticas insurgentes de resistir, (re)existir y (re)vivir. Serie Pensamiento decolonial. QuitoEcuador: Ediciones Abya-Yala, 2013.

FREIRE, Paulo. Pedagogia da autonomia: saberes necessários à prática educativa. São Paulo: Paz e Terra, 1996.

FREIRE, Paulo. Pedagogia do Oprimido. São Paulo: Paz e Terra, 2005.

GROSFOGUEL, Ramón. Para descolonizar os estudos de economia política e os estudos pós-coloniais: transmodernidade, pensamento de fronteira e colonialidade global. Revista Crítica de Ciências Sociais, n.80, Março 2008, p. 115-147.

MIGNOLO, Walter. Historias locales/diseños globales: colonialidad, conocimientos subalternos y pensamento fronterizo. Ediciones Akal, S. A, 2011.

MOHANTY, Chandra. T. Bajo los ojos de occidente. En: Navaz, L. S., Hernández, A. (eds): Descolonizando el Feminismo: teorías y prácticas desde los márgenes, ed. Cátedra, Madrid, 2008.

PAREDES, Julieta. Hilando fino desde el feminismo comunitário. Mujeres creando comunidad. La Paz, 2010.

PAREDES, Julieta. Una sociedad en estado y con estado despatriarcalizador. Cochabamba: Diciembre, 2011.

PORTO-GONÇALVES, Carlos. W. Entre América e Abya Yala - tensões de territorialidades. Desenvolvimento e Meio Ambiente, n. 20, p. 25-30, jul./dez. Editora UFPR, 2009.

QUIJANO, Aníbal. Colonialidade do poder, eurocentrismo e América Latina. En: Lander, Edgar. (Org.). A colonialidade do saber: eurocentrismo e ciências sociais. Perspectivas latino-americanas. Colección Sur Sur, CLACSO, Ciudad Autónoma de Buenos Aires, Argentina. Setembro, 2005.

QUIJANO, Aníbal. Colonialidad del Poder y Clasificacion social. En. Wallerstein, Immanuel. Journal of world systems research, v.2. California, 2000.

SILVA, Janssen. F. Sentidos de Avaliação da Educação e no Ensino e no Currículo na Educação Básica através dos Estudos Pós-Coloniais Latino-americanos. Espaço do Currículo, v.8, n.1, p.49-64, Janeiro a Abril, 2015.

SILVA, Janssen. F. Sentidos da Educação na Perspectiva dos estudos pós-coloniais latino-americano. En. Martins, P. H., Silva, M. A., Lira, B. F., Leão, E. L. S. Guía sobre post-desarrolo y nuevos horizontes. Ciudad Autónoma de Buenos Aires: Estudios Sociológicos Editora, 2014. 
ii Utilizamos o termo no plural por entendermos que, em diferentes tempos e espaços, foram construídos distintos movimentos feministas e, portanto, diferentes perspectivas de feminismo.

ii Destacamos que Abya Yala é uma das nomeações atribuídas a América pelos povos Kuna, que "significa Terra Madura, Terra Viva ou Terra em florescimento e é sinônimo de América" (PORTO-GONÇALVES, 2009, p. 25).

iii Destacamos o uso dos termos "Norte e Sul" no intuito de evidenciarmos que o local geográfico não corresponde, necessariamente, ao lugar epistêmico, visto que feministas do Norte incluem as do Sul localizadas, geopoliticamente, no Norte (ESPINOSA MIÑOSO, 2009). 